\title{
Erratum to: Androgen therapy in women: for whom and when
}

\author{
Nicola Pluchino - Arianna Carmignani • \\ Alessandra Cubeddu • Anna Santoro • \\ Vito Cela • Tania Errasti
}

Published online: 12 October 2013

(c) Springer-Verlag Berlin Heidelberg 2013

Erratum to: Arch Gynecol Obstet (2013) 288:731-737

DOI 10.1007/s00404-013-2969-7

Unfortunately, the author's name was published incorrectly as Tania Errasti Alcalà in the original publication. The correct name should read as Tania Errasti.

The online version of the original article can be found under doi:10.1007/s00404-013-2969-7.

N. Pluchino - A. Carmignani - A. Cubeddu $(\bowtie) \cdot$ A. Santoro ·

V. Cela $\cdot$ T. Errasti

Department of Reproductive Medicine and Child Development,

Division of Gynecology and Obstetrics, University of Pisa,

Via Roma 35, 56100 Pisa, Italy

e-mail: cubeddissima@hotmail.com

N. Pluchino

e-mail: nicola.pluchino@med.unipi.it 